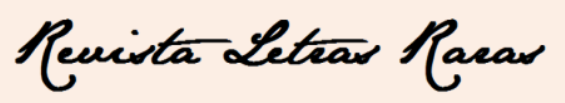

ISSN: 2317-2347 - Vol. 5, Ano 5, № 2 - 2016

\title{
Globalização, Língua Inglesa e a relação opressora com as Línguas Africanas
}

Paula de Sousa Costa*

\section{RESENHA DO LIVRO:}

RODRIGUES, Ângela. L. A língua inglesa na África: opressão, negociação e resistência. $1^{\circ}$ ed. São Paulo: Editora Unicamp, 2011.

A obra A língua inglesa na África: opressão, negociação e resistência (2011) é resultado de uma pesquisa de pós-doutorado da autora, Ângela Lamas Rodrigues, na Universidade de São Paulo, sobre os impactos da anglofonia nos países africanos. Para tanto, a autora realiza um panorama da história da língua inglesa no continente africano como herança do colonizador, que reflete a opressão no processo de colonização em detrimento das línguas africanas.

A autora discorre acerca do lugar e importância das línguas africanas, bem como a respeito da língua inglesa como um fenômeno global que estabeleceu sua supremacia em relação às línguas autóctones nos países africanos. Para ela, é preciso refletir sobre a condição das línguas africanas quanto a sua situação de prestígio ou desprestígio, seu valor, alcance e força na atualidade. Sendo assim, é importante ressaltar a relação de língua dominante e línguas minoritárias devido às questões, políticas, culturais e econômicas.

Nessa perspectiva, enfatiza-se que se faz necessário entender a globalização neoliberal como continuidade de políticas colonialistas, devidamente readaptadas aos tempos atuais, isso devido à dependência dos países pobres em relação aos centros de poder, o que acarreta no enfraquecimento do Estado, e consequentemente, submete-se a "uma nova versão do imperialismo" (RODRIGUES, 2011).

\footnotetext{
* Mestranda em Linguagem e Ensino no Programa de Pós-graduação da UFCG, especialista pela FASP - PB em Língua e literatura, e graduada pela UECE em Língua Portuguesa/ Inglesa. Tem experiência na área de Letras, com ênfase em Língua Inglesa e Literaturas, atuando principalmente nas áreas: literatura africana de língua inglesa e a abordagem do texto literário na aula de língua estrangeira.
} 


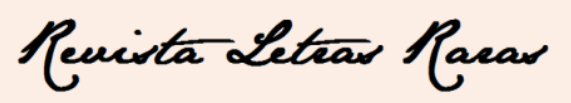

ISSN: 2317-2347 - Vol. 5, Ano 5, № 2 - 2016

Rodrigues (2011) realiza um apanhado das línguas africanas na era do inglês global em cada país, segundo o qual sinaliza que a África possui aproximadamente 2.100 línguas, embora algumas línguas ainda não tenham sido catalogadas enquanto outras estão em processo de extinção. A autora classifica essas línguas em vulneráveis, definitivamente ameaçadas, severamente ameaçadas e criticamente ameaçadas, expondo, assim, o espaço em que essas línguas africanas disputam entre si e vivem em condição de marginalidade em relação à língua inglesa, tanto pelo capitalismo financeiro quanto pela permanência da anglofonia nestes países.

Desse modo, “O fim da colonização não significou uma mudança política, cultural e social capaz de reverter ou menos repensar o lugar tomado pelas línguas europeias. Para detrimento das línguas africanas autóctones, aquelas permanecem como capital cultural precioso e restrito a poucos." (RODRIGUES, 2011, p. 31) Partindo dessa ideia, a problemática linguística na África é resultado também da opressão durante a colonização que marginalizou as línguas desses povos, e perpetua-se em um conjunto de dilemas, que afligem os povos desse continente atualmente. Um desses dilemas é a preferência pelo uso de línguas europeias nos domínios oficiais dos países africanos após a independência, evidenciando uma relação de continuidade com as práticas linguísticas colonialistas.

O termo afrophone apresenta-se em oposição às expressões lusófono, francófono ou anglófono, para denotar que o povo africano é antes de tudo falante das línguas africanas, e destacar que essa expressão remete e engloba o plurilinguísmo existente em cada país e/ou comunidade do continente.

Os laços do continente africano com a língua inglesa iniciaram-se com os navegadores britânicos interessados em comércio e escravos. O inglês, portanto, passou a ser ensinado pelas missões empreitadas pelo colonizador, também para facilitar a comunicação e comércio. Instituindo um modelo de educação e política alienante, "que até hoje interfere na promoção e oficialização de línguas africanas autóctones, criando condições para que o inglês mantenha seu status como língua hegemônica" (RODRIGUES, 2011, p. 46). Outro fato importante, é que o ensino de inglês, após a Segunda Guerra Mundial, foi considerado instrumento essencial no projeto de modernização do continente. Para os políticos africanos, o inglês era a língua que propiciaria a emancipação e libertação, o que evidência a ideologia construída ao redor da língua. 


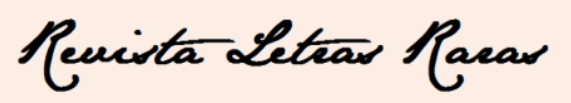

ISSN: 2317-2347 - Vol. 5, Ano 5, № 2 - 2016

A obra apresenta três estudos de casos: Tanzânia, Quênia e Uganda, sobre como a língua inglesa está presente nesses países, o número de habitantes, o número de falantes de inglês, as línguas autóctones e como se estabelece o sistema educacional em cada país. Assim, percebe-se que os países permanecem com a mentalidade colonizadora entre as elites, que consideram o inglês como padrão de língua desenvolvida e modernizante, superior as línguas africanas.

Porém, poderia se dizer que a África como um todo, tem como sua maior aliada a utilização dessas línguas autóctones no cotidiano das populações, na forma como são reconstruídas e reproduzidas diariamente, seja em regiões isoladas ou na cultura popular das grandes cidades e favelas.

Rodrigues (2011) traz ainda, como exemplos de negociação e resistência a essa imposição da língua inglesa, as políticas linguísticas de Chinua Achebe e Ngũgĩ wa Thiong'o. Embora, estes escritores africanos apresentam posturas diferentes em relação à língua inglesa, ambos receberam a educação e a língua nos moldes dos colonizadores. Dessa forma, reconhecem a complexidade da questão linguística na África levando em conta os embustes do colonialismo e a globalização.

Chinua Achebe, escritor nigeriano, está entre os mais importantes romancistas da África, é visto como o "inventor" do romance africano, pois foi pioneiro em contar a história da África em suas obras pelo ponto de vista africano e não ocidental. Porém, mantêm uma relação de negociação de culpa por escrever suas obras na língua do colonizador, ignorando a problemática das línguas africanas. Para ele, escrever na língua do colonizador o torna reconhecido no ocidente, e é uma forma de levar a conhecer a cultura e a voz do povo africano por meio da literatura. Uma das maneiras encontradas por Achebe "para negociar essa culpa é definir a causa primordial de sua decisão em escrever na língua inglesa como um trauma social generalizado produzido pelo colonialismo.” (RODRIGUES, 2011, p. 92)

Ngũgĩ wa Thiong'o, no entanto, se preocupa com o ensino de literatura no sistema educacional, é reconhecido pela ruptura com a educação formal colonialista e rejeição da língua inglesa. Sua preocupação com a questão linguística na África leva-o a participar de um espaço criado pela população de uma comunidade em seu país, Quênia (Vila Kamirriithu), no qual o escritor participou como educador. Para Thiong'o, essa experiência representou uma "ruptura epistemológica com seu passado" (RODRIGUES, 2011, p. 104), por causa da sua 


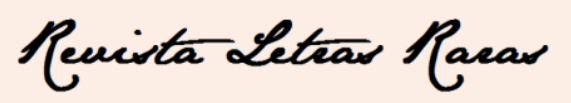

ISSN: 2317-2347 - Vol. 5, Ano 5, № 2 - 2016

participação é preso, depois foi exilado por mais de 20 anos, durante esse período o autor escreve várias obras onde predomina a língua materna, mas também traduzida para o inglês e outras línguas.

Embora o exílio tenha significado o fim dos projetos educacionais de Thiong'o no Quênia, proporcionou a elaboração de uma política linguística que se baseia na necessidade de reconhecer o processo de colonização mental, a importância do intelectual e do escritor africano na valorização das línguas maternas e na necessidade de encorajar um diálogo entre as línguas marginalizadas e dominantes.

Em suas considerações finais, Rodrigues (2011) conclui que o discurso ideológico acerca da língua inglesa se apresenta como continuidade ao discurso colonialista britânico, o qual é produzido e alimentado pela elite africana atreladas a políticas econômicas e culturais. Dessa forma, aponta-se para a necessidade de pensar em planejamentos linguísticos distintos e apropriados que contemple cada situação específica, já que o continente africano possui realidades muito diferentes: "parece necessário que a questão linguística na África seja tratada a partir de uma perspectiva que leve em conta diferentes contextos históricos, políticos e sociais que caracterizam cada nação e as diversas sociedades africanas." (RODRIGUES, 2011, p. 120)

Dessa forma, a autora chama a atenção também, para a necessidade de interrogar e desmistificar o inglês como uma língua de poder, sobretudo, para reavaliar rigorosamente o lugar das línguas africanas. Além disso, a obra alerta para os prejuízos que a colonização deixou na cultura, na economia, bem como na língua desses países que vivem hoje uma nova forma de imperialismo que tornou os países africanos, por sua condição financeira mais vulneráveis, dependentes das potências hegemônicas atuais.

Vale ressaltar, ainda, que o colonialismo é o principal responsável pela construção dos estereótipos negativos construídos acerca do continente africano, e a ideia singular que envolve-o num manto de pobreza e selva. Portanto, a obra nos faz refletir sobre a diversidade da África, abrindo as nossas mentes para pensar nessa pluralidade geográfica, climática, econômica, cultural e linguística, tornando assim necessário reconhecer a existência não apenas da visão colonizadora da África, mas das diversas Áfricas que formam esse continente.

Essas discussões trazidas por Rodrigues (2011) são relevantes por tentar desmistificar os estereótipos sobre o continente africano, principalmente pelo viés linguístico, mostrando a

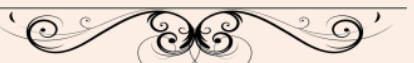




\section{Reuista Leteras Rear}

ISSN: 2317-2347 - Vol. 5, Ano 5, № 2 - 2016

complexa realidade das línguas africanas diante da hegemonia da língua inglesa. Mais do que uma leitura, este estudo nos faz desconstruir conceitos e reconstruir nosso pensamento, ampliando nossa visão para um olhar mais crítico e justo em relação a problemática linguística na África.

Recebido em: 11/09/2016

Aceito em: 30/09/2016 